\title{
Ectopia renal cruzada con fusión
}

\author{
M. de la Cruz Ruiz, A. Vicens Vicens, M. Ozonas Moragues
}

Servicio de Urología. Hospital Universitario Son Dureta. Palma de Mallorca

Actas Urol Esp 2006; 30 (3): 342

$\mathrm{P}$ aciente de 65 años que consulta por síntomas obstructivos infravesicales. El estudio ecográfico informa de la ausencia de riñón izquierdo, con riñón derecho de mayor tamaño (supuestamente compensador. Se realiza UIV para completar estudio urológico morfofuncional, encontrándose la imagen de ectopia renal cruzada (ERC) fusionada, con riñón izquierdo situado caudalmente, fusionado al polo inferior del derecho, "en L"; y ambos malrotados. No presenta sintomatología en relación con la ERC.

Existen diversas teorías para tratar de explicar el origen embriogénico de esta anomalía ${ }^{1}$. Su incidencia en autopsias es de $1 / 7.500$, mientras que en estudios clínicos es de 1/15.000 (Sole F., 1973), he-

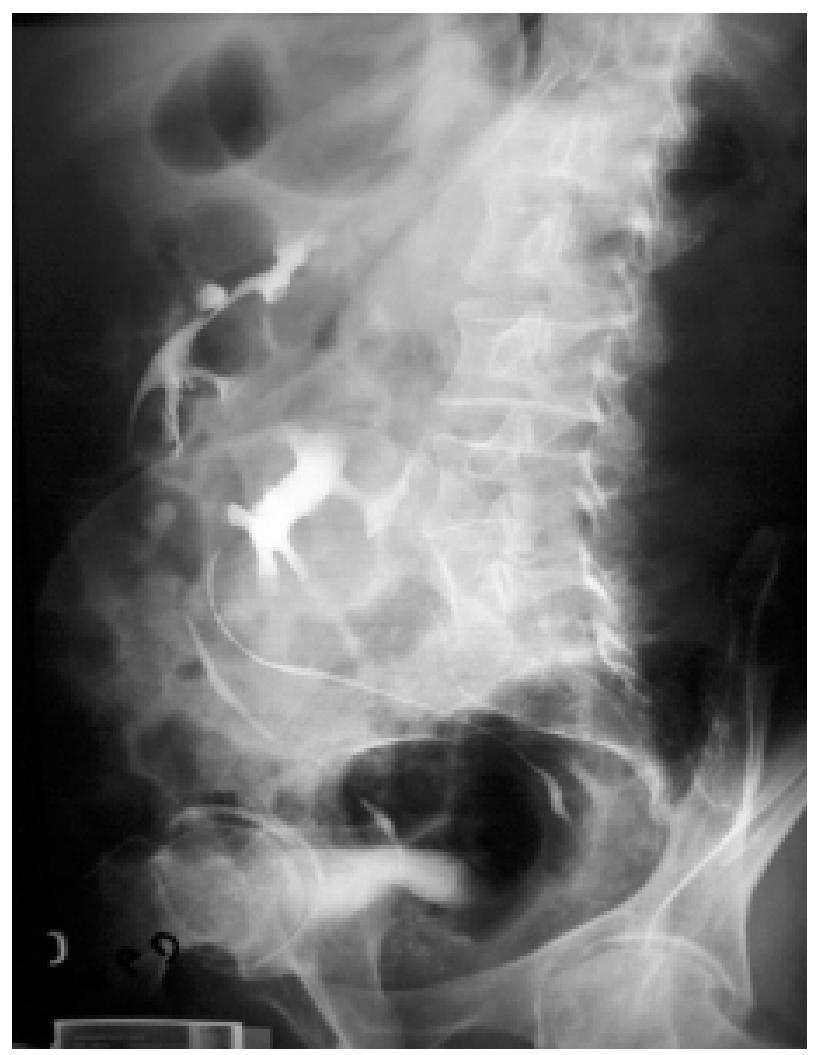

FIGURA 1 cho que se explica al ser frecuentemente asintomática. Es más frecuente en el sexo masculino $(1,4: 1)$ y la ectopia cruzada hacia la izquierda (3:1).

\section{REFERENCIAS}

1. Sousa Escandón MA, González Rodríguez A, García Figueiras R, Lapena Villarroya JA, Armesto Fernández M, Gómez Torreiro E et al. Ectopia renal cruzada: posibilidades radiológicas de la TAC helicoidal. Actas Urol Esp 2002; 26(5):313-319.

Dra. M. de la Cruz Ruiz

Servicio de Urología. Hospital Univ. Son Dureta. Andrea Doria s/n - 07014 Palma de Mallorca

E-mail: mdelacruz@hsd.es

(Trabajo recibido el 19 de mayo de 2005)

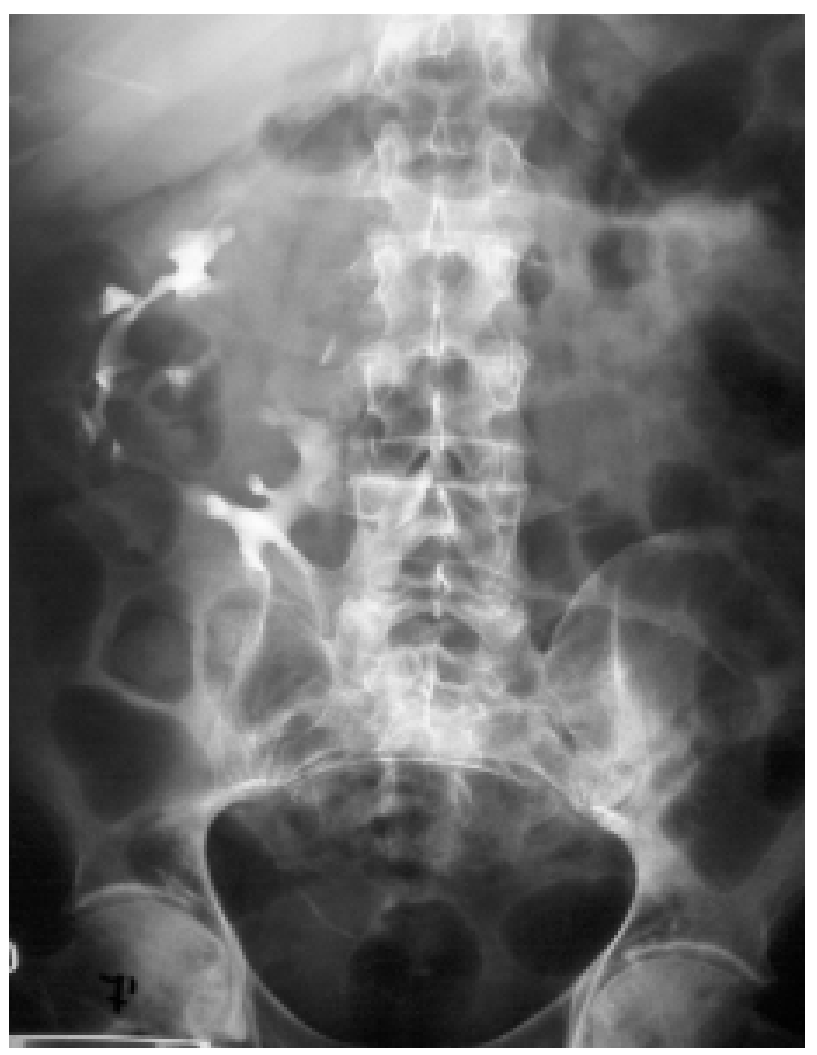

FIGURA 2 